\title{
SOME DISCRETE FRACTIONAL LYAPUNOV-TYPE INEQUALITIES
}

\author{
Rui A. C. FERREIRA
}

Abstract. In this work we obtain Lyapunov-type inequalities for two-point conjugate and rightfocal boundary value problems depending on discrete fractional operators $\Delta^{\alpha}, 1<\alpha \leqslant 2$.

Mathematics subject classification (2010): Primary 34A08, 26D15; Secondary 39A12. Keywords and phrases: fractional difference, Lyapunov-type inequality.

\section{REFERENCES}

[1] F. M. Atici And P. W. Eloe, Initial value problems in discrete fractional calculus, Proc. Amer. Math. Soc. 137, 3 (2009), 981-989.

[2] F. M. Atici And S. ŞEngÜL, Modeling with fractional difference equations, J. Math. Anal. Appl. 369, 1 (2010), 1-9.

[3] F. M. Atici AND P. W. Eloe, Two-point boundary value problems for finite fractional difference equations, J. Difference Equ. Appl. 17, 4 (2011), 445-456.

[4] Y. CHEN AND X. TANG, The difference between a class of discrete fractional and integer order boundary value problems, Commun. Nonlinear Sci. Numer. Simul. 19, 12 (2014), 4057-4067.

[5] S. S. Cheng, A discrete analogue of the inequality of Lyapunov, Hokkaido Math. J. 12, 1 (1983), $105-112$.

[6] R. A. C. Ferreira, A discrete fractional Gronwall inequality, Proc. Amer. Math. Soc. 140, 5 (2012), $1605-1612$.

[7] R. A. C. FERREIRA, Existence and uniqueness of solution to some discrete fractional boundary value problems of order less than one, J. Difference Equ. Appl. 19, 5 (2013), 712-718.

[8] R. A. C. Ferreira, A Lyapunov-type inequality for a fractional boundary value problem, Fract. Calc. Appl. Anal. 16, 4 (2013), 978-984.

[9] R. A. C. FERREIRA, On a Lyapunov-type inequality and the zeros of a certain Mittag-Leffler function, J. Math. Anal. Appl. 412, 2 (2014), 1058-1063.

[10] C. S. GoodRICH, Solutions to a discrete right-focal fractional boundary value problem, Int. J. Difference Equ. 5, 2 (2010), 195-216.

[11] C. S. Goodrich, A convexity result for fractional differences, Appl. Math. Lett. 35 (2014), 58-62.

[12] M. G. KREIN, On certain problems on the maximum and minimum of characteristic values and on the Lyapunov zones of stability, Amer. Math. Soc. Transl. (2) 1 (1955), 163-187.

[13] M. Holm, Sum and difference compositions in discrete fractional calculus, Cubo 13, 3 (2011), 153184.

[14] A. Liapounoff, Problème Général de la Stabilité du Mouvement, Annals of Mathematics Studies, no. 17, Princeton Univ. Press, Princeton, NJ, 1947.

[15] M. JLELI AND B. S AMET, Lyapunov-type inequalities for a fractional differential equation with mixed boundary conditions, Preprint.

[16] K. S. Miller AND B. Ross, Fractional difference calculus, in Univalent functions, fractional calculus, and their applications (Köriyama, 1988), 139-152, Horwood, Chichester, 1989. 